\title{
Influence of transport and mixing in autumn on stratospheric ozone variability over the Arctic in early winter
}

\author{
D. Blessmann, I. Wohltmann, and M. Rex \\ Alfred Wegener Institute for Polar and Marine Research, Potsdam, Germany \\ Correspondence to: I. Wohltmann (ingo.wohltmann@awi.de) \\ Received: 14 May 2012 - Published in Atmos. Chem. Phys. Discuss.: 13 June 2012 \\ Revised: 22 August 2012 - Accepted: 24 August 2012 - Published: 6 September 2012
}

\begin{abstract}
Early winter ozone mixing ratios in the Arctic middle stratosphere show an interannual variability of about $10 \%$. We show that ozone variability in early January is caused by dynamical processes during Arctic polar vortex formation in autumn (September to December). Observational data from satellites and ozone sondes are used in conjunction with simulations of the chemistry and transport model ATLAS to examine the relationship between the meridional and vertical origin of air enclosed in the polar vortex and its ozone amount. For this, we use a set of artificial model tracers to deduce the origin of the air masses in the vortex in January in latitude and altitude in September. High vortex mean ozone mixing ratios are correlated with a high fraction of air from low latitudes enclosed in the vortex and a high fraction of air that experienced small net subsidence (in a Lagrangian sense). As a measure for the strength of the Brewer-Dobson circulation and meridional mixing in autumn, we use the Eliassen-Palm flux through the mid-latitude tropopause averaged from September to November. In the lower stratosphere, this quantity correlates well with the origin of air enclosed in the vortex and reasonably well with the ozone amount in early winter.
\end{abstract}

\section{Introduction}

Stratospheric ozone mixing ratios over the Arctic are influenced by dynamical and chemical processes. While chemical processes, particularly in winter and spring, are reasonably well understood (e.g. Frieler et al., 2006; WMO, 2011), uncertainties remain in understanding the quantitative effect of dynamical processes on the high latitude ozone layer. Dynamics and chemistry in autumn have received relatively lit- tle attention so far (e.g. Kawa et al., 2003; Tilmes et al., 2006), even though they set the initial conditions for the winter season.

At the end of summer in early September, just before the polar vortex forms, the interannual variability in the ozone abundance is low compared to the winter and spring season throughout the Arctic stratosphere, because ozone variability induced earlier in the year declines toward the chemically determined equilibrium (Fahey and Ravishankara, 1999; Fioletov and Shepherd, 2003). Nevertheless, a fair amount of interannual variability is introduced in the Arctic ozone mixing ratios during autumn, particularly in the middle stratosphere between $500-800 \mathrm{~K}$, where the ozone profile is relatively constant at values of about 3-4 ppm, but shows an interannual variability of about $10 \%$ (see also Kawa et al., 2005). This variability is related to wave activity and mixing from lower latitudes (Rosenfield and Schoeberl, 2001; Kawa et al., 2003).

The interannual variability increases during the vortex formation period from September to December as illustrated in Fig. 1. Figure 1 shows monthly mean vertical profiles of ozone mixing ratios inside the polar vortex for each month from September to December and the years 1991-2005. The vortex is defined as the area north of $65^{\circ} \mathrm{N}$ equivalent latitude here and the profiles are based on the ozone data set presented in the next section. The mean standard deviation of ozone mixing ratios between $500-700 \mathrm{~K}$ increases from $0.13 \mathrm{ppm}$ in September to $0.24 \mathrm{ppm}$ in December. To put these numbers into perspective: the highest standard deviations are observed in the polar vortex in winter (December to March) and are about $0.4 \mathrm{ppm}$.

In the Arctic stratosphere, the circulation in summer is characterized by slow easterly motion, preventing the vertical 

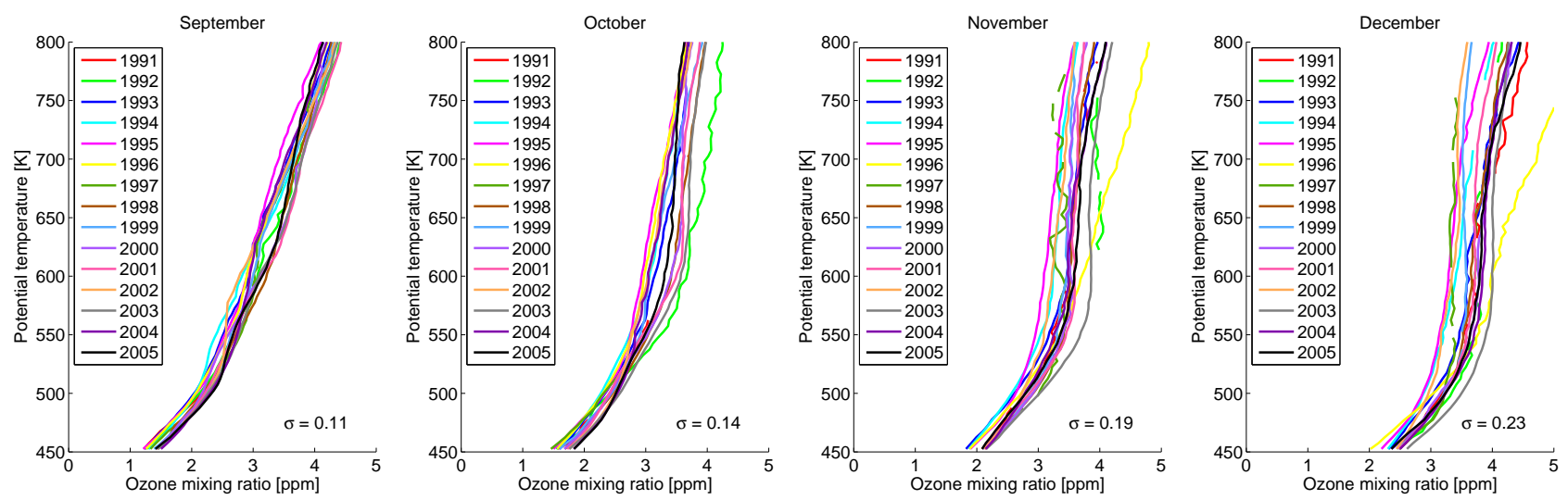

Fig. 1. Monthly mean profiles of ozone mixing ratios in the polar vortex for the months from September to December and the years $1991-$ 2005. The vortex is defined as the area north of $65^{\circ} \mathrm{N}$ equivalent latitude. Measurements are from satellites and ozone sondes (see text for details). The standard deviation of the monthly mean ozone mixing ratios in the vortex between $500-700 \mathrm{~K}$ is shown for every month in the lower right corner.

propagation of planetary scale waves from their source regions in the troposphere to the stratosphere (Charney and Drazin, 1961, see also Andrews et al., 1987, for a detailed review of middle atmosphere dynamics). Additionally, chemical processes lead to a strong meridional gradient in the ozone field at this time.

After autumnal equinox thermal emission leads to subsidence of air over the polar region and to a reversal of the circulation, westerly winds and eventually to the formation of the polar vortex (Schoeberl and Hartmann, 1991; Kawa et al., 2003). Then the strong westerlies surrounding the polar vortex again prevent the vertical propagation of planetary waves and suppress meridional mixing. But during the vortex formation period weak westerlies also permit waves with shorter wave lengths to propagate freely into the stratosphere and meridional mixing is enhanced. The meridional mixing introduces pronounced variability in the ozone abundance in high latitudes, which is later enclosed by the polar vortex. We show that the degree to which these waves transport low latitude air and ozone into the Arctic depends on the level of wave activity in the troposphere during this brief sensitive period, which typically lasts from the middle of September to the middle of November. In addition, we show that the latitudinal origin and the amount of subsidence the air experienced are correlated to the ozone amount enclosed in the vortex in early winter. This is in line with the general accepted mechanism that vortex ozone abundances are the result of a balance of mixing and subsidence and that the strength of both subsidence and mixing are determined by the amount of wave breaking in the stratosphere (Andrews et al., 1987). In a companion paper, we show that below a critical altitude (about $750 \mathrm{~K}$ ), the chemical lifetime of ozone is long enough to let transport dominate over chemistry (Blessmann et al., 2012)
We examine the dynamical processes in autumn which lead to the observed variability in early winter on the basis of measured ozone data and model runs driven by ECMWF (European Centre for Medium Range Weather Forecasts) reanalyses. In Sect. 2, we present the ozone data set and the chemistry transport model used in this study. In Sect. 3, we show that the origin of air masses enclosed in the vortex and vortex mean ozone mixing ratios in early winter are related. For this, we use a set of artificial tracers, which are passively transported in the model and initialized in early autumn to values different from zero only in a limited spatial domain (see e.g. Günther et al., 2008). In Sect. 4, we show that the origin of air is related to the strength of the Brewer-Dobson circulation and meridional mixing. For this, we show correlations of the origin of air with the Eliassen-Palm flux through the midlatitudes in autumn. Finally, we show in Sect. 5 that EP flux and ozone are also related. Conclusions are given in Sect. 6.

Earlier studies show surprisingly high correlations between late winter total ozone and early winter ozone mixing ratios (Kawa et al., 2005; Sinnhuber et al., 2006). E.g. the correlation between November ozone mixing ratios at $600 \mathrm{~K}$ from SBUV and March total ozone from TOMS is as high as 0.78 (Kawa et al., 2005). This is much higher than the direct effect expected if the variability of the partial column from $500-800 \mathrm{~K}$ in early winter would be conserved until late winter (Kawa et al., 2005). However, the causal relationships remain unclear and are not in the scope of this study.

\section{Data and model}

The study is based on an ozone data set for the Arctic region, the ECMWF ERA Interim reanalysis (Dee et al., 2011) and model output from the Lagrangian chemistry and transport model ATLAS for the winters 1991/1992 to 2008/2009. 


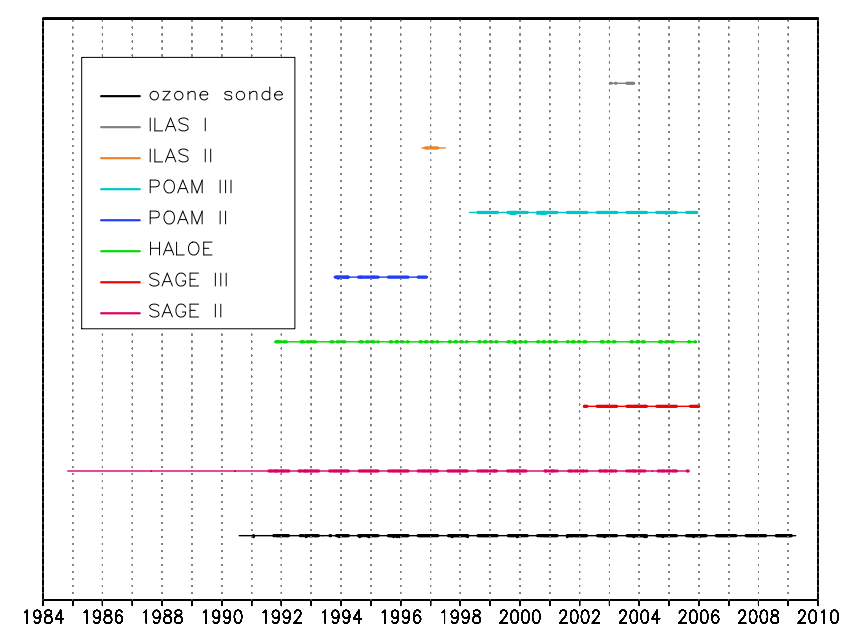

Fig. 2. Availability of ozone measurements from satellites and ozone sondes from 1991 to 2009.

\subsection{Observational data}

The observational data set includes measurements from ozone sondes and 7 satellite based instruments. Data is available north of $30^{\circ} \mathrm{N}$ from 1 August to 31 March for the time period 1991/1992 to 2008/2009.

All ozone measurements are binned and averaged in equivalent latitude bins with 5 degree resolution and in temporal bins with a resolution of 10 days. Equivalent latitude is calculated from data of the ECMWF ERA Interim reanalysis. Equivalent latitude is defined as the latitude an area enclosed by a potential vorticity contour would have, if it would be circular and centered at the pole (e.g. Butchart and Remsberg, 1986). The vertical resolution of the data set is $5 \mathrm{~K}$ between $450 \mathrm{~K}$ and $1000 \mathrm{~K}$.

The satellite measurements are from the solar occultation instruments HALOE (Halogen Occultation Experiment) (Russell III et al., 1993), SAGE II \& III (Stratospheric Aerosol and Gas Experiment) (McCormick et al., 1989), POAM II \& III (Polar Ozone and Aerosol Measurement) (Lumpe et al., 1997, 2002) and ILAS I \& II (Improved Limb Spectrometer) (Nakajima et al., 2004). Figure 2 shows the time periods where measurements are available from the individual satellite instruments. No bias correction between the satellite instruments is applied, because potential instrumental biases are much smaller than the interannual variability of ozone in the region studied here. All instruments cover the complete altitude range of the data set and have a vertical resolution of about $1-2 \mathrm{~km}$.

The ozone data set consists of around 14000 ascents of ozone sondes from 55 stations, which are shown in Fig. 3. The measurements are checked manually for consistency and accuracy. After 2006, the data set is only based on ozone sondes. In the time periods where ozone sonde data and satellite

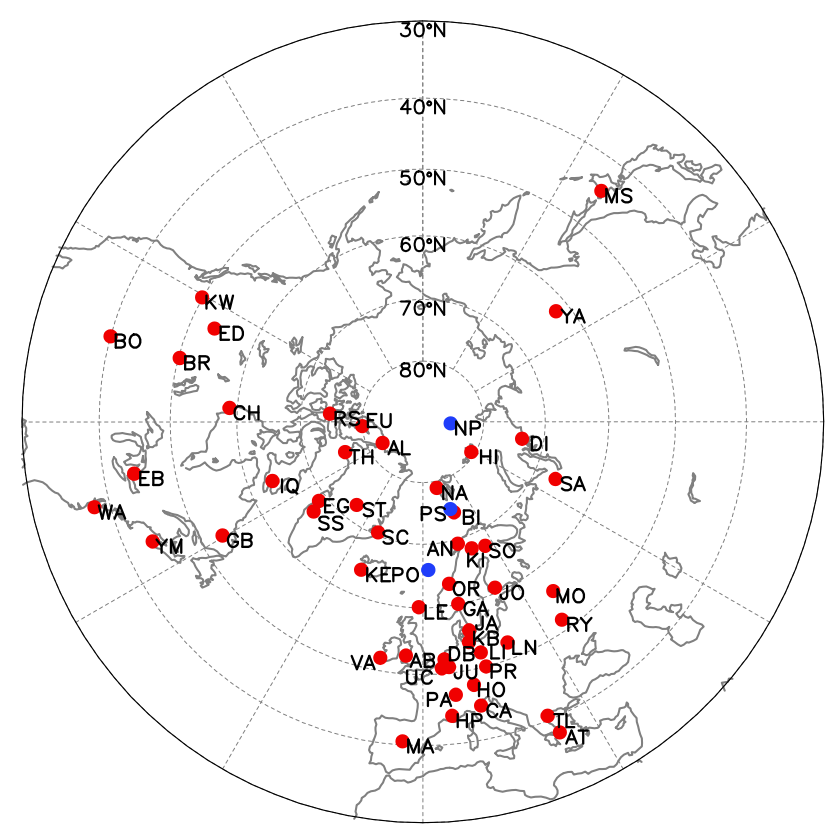

Fig. 3. Ozone sonde stations used in the ozone data set. Ships and the ice drifting station NP-35 are shown in blue.

data overlap, ozone sondes and satellite instruments agree within $0.4 \mathrm{ppm}$.

\subsection{Model}

ATLAS is a global chemistry and transport model with a Lagrangian (trajectory-based) transport and mixing scheme and stratospheric chemistry (Wohltmann and Rex, 2009; Wohltmann et al., 2010). Lagrangian models have several advantages over conventional Eulerian models, in particular no spurious numerical diffusion and a more realistic transport of conserved tracers.

We have based our model runs on ERA Interim reanalysis data (Dee et al., 2011) with a horizontal resolution of $2 \times 2$ degrees, 60 model levels and a temporal resolution of $6 \mathrm{~h}$. Trajectories are integrated with a $30 \mathrm{~min}$ time step. The vertical coordinate is a hybrid coordinate, which is to a good approximation a potential temperature coordinate in the vertical domain used. Vertical motion is driven by ERA Interim heating rates (clear sky). The horizontal model resolution is $100 \mathrm{~km}$ and the model domain extends from 350 to $1500 \mathrm{~K}$. The critical Lyapunov exponent, which adjusts the mixing strength, is set to 4 days $^{-1}$, see Wohltmann and Rex (2009). The transport scheme of the ATLAS model has been shown to reproduce observed long-lived tracer fields and tracer correlations very well after several months of simulation time, and a detailed validation of the ATLAS transport properties is presented in Wohltmann and Rex (2009). The chemistry module is not activated for the model runs, so that only the transport and mixing module is used. 


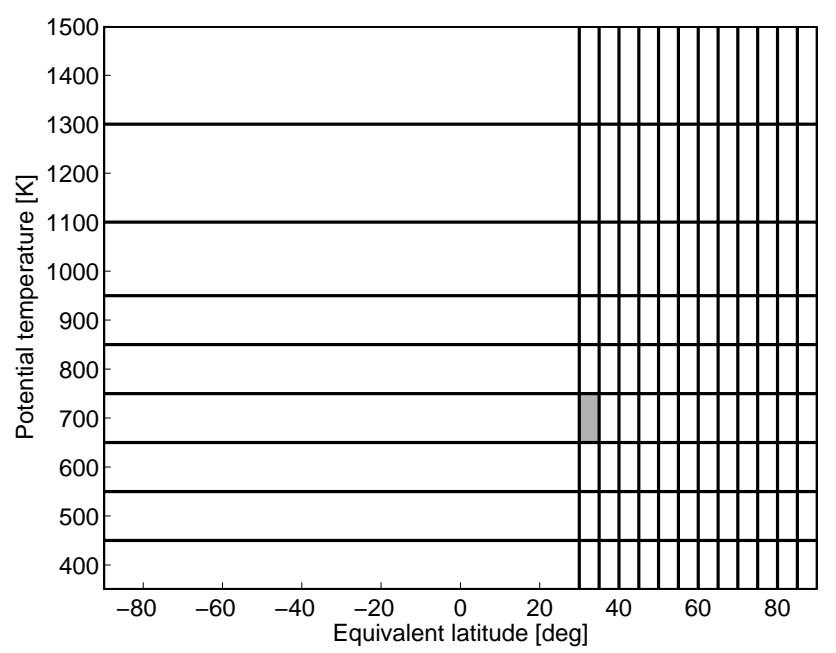

Fig. 4. Setup of the tracers at the start of the model run. The tracer shown in Fig. 5 is highlighted.

A realistic transport of the tracers requires the reanalysis to contain a realistic representation of the observed BrewerDobson circulation. The ECMWF ERA Interim reanalysis has been shown to capture the basic features of the observed Brewer-Dobson circulation (Dee et al., 2011). In particular, the age of air is much more reasonable than in the preceding ECMWF ERA-40 reanalysis and within the error bars of observations (see Fig. 28 in Dee et al., 2011 or Legras and Fueglistaler, 2009). There are also some known discrepancies, like a too fast ascent at the tropics, but the ERA Interim data set is probably the best available reanalysis in the moment.

\subsection{Setup of the origin tracers}

Artificial tracers of air mass origin have been used in the past to determine transport pathways in the atmosphere (e.g. Günther et al., 2008). Here, 117 tracers are initialized on 1 September in every year (1991/1992-2008/2009) to be able to calculate the origin of air masses enclosed in the vortex in early winter. The mixing ratio of each of these tracers is set to one inside a certain equivalent latitude interval and potential temperature interval and zero outside these intervals to identify air masses from a certain spatial origin. Figure 4 shows the arrangement of tracers at the beginning of the model run. The tracers are initialized in a non-overlapping fashion, filling the spatial domain of the model. The potential temperature intervals start at $350 \mathrm{~K}$ in $100 \mathrm{~K}$ steps up to $950 \mathrm{~K}$. The last three intervals are 950-1100 K, 1100-1300 K and 1300$1500 \mathrm{~K}$. The equivalent latitude intervals reach from $30^{\circ} \mathrm{N}$ in 5 degree steps up to $90^{\circ} \mathrm{N}$. The first equivalent latitude interval is a special case and encloses the equivalent latitudes from $90^{\circ} \mathrm{S}$ to $30^{\circ} \mathrm{N}$.

The tracers are transported and mixed down to lower values than one in the course of the model run. This kind of

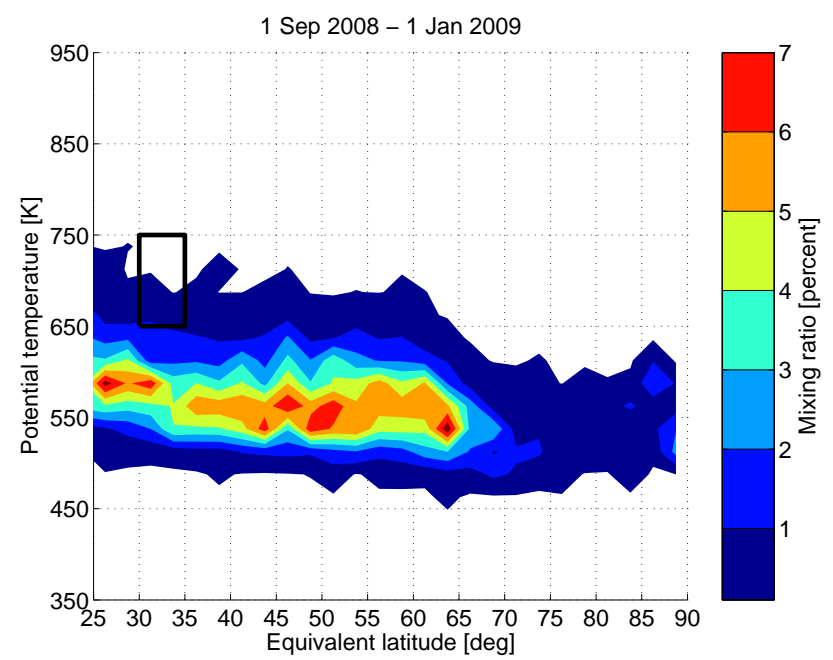

Fig. 5. Zonal mean tracer mixing ratio of a selected origin tracer $\left(30-35^{\circ} \mathrm{N}\right.$ equivalent latitude and $\left.650-750 \mathrm{~K}\right)$ at the start of a model run (1 September 2008, the black box is the area of mixing ratios of $100 \%$ ) and in early winter (1 January 2009, filled contours).

tracer arrangement enables us to determine the origin of air by examining the fractions that the single tracers contribute to an air mass later in the model run. The fractions of the single tracers add up to one by definition at every model air parcel and can directly be interpreted as the percentage of air from a certain origin.

As an example, Fig. 5 shows the zonal mean tracer mixing ratios of a selected origin tracer $\left(30-35^{\circ} \mathrm{N}\right.$ equivalent latitude and $650-750 \mathrm{~K}$ ) at the start of a model run (1 September 2008) and in early winter (1 January 2009).

In the following, we will typically average over the tracer mixing ratios of all air parcels inside the polar vortex, which directly gives the fractions of air inside the vortex originating from a certain equivalent latitude and potential temperature interval on 1 September.

In some cases, it is also convenient to add up several tracers. E.g. to determine the fraction of air originating from equivalent latitudes south of $30^{\circ} \mathrm{N}$ on 1 September, we add up all tracers south of $30^{\circ} \mathrm{N}$, i.e. the first column of tracers in Fig. 4.

\section{Ozone and origin of air}

Here we show that the origin of air masses and ozone mixing ratios in the vortex are related. As an example, Fig. 6 shows the time series of vortex mean ozone mixing ratios averaged over 525-575 K in early winter (30 December-8 January, 1992 to 2009 , black). The vortex is defined as the area north of $65^{\circ} \mathrm{N}$ equivalent latitude here and in the subsequent plots. As the reference time period for early winter, we use 30 December-8 January throughout the study. Superimposed on the ozone time series is a time series of the fraction of air 


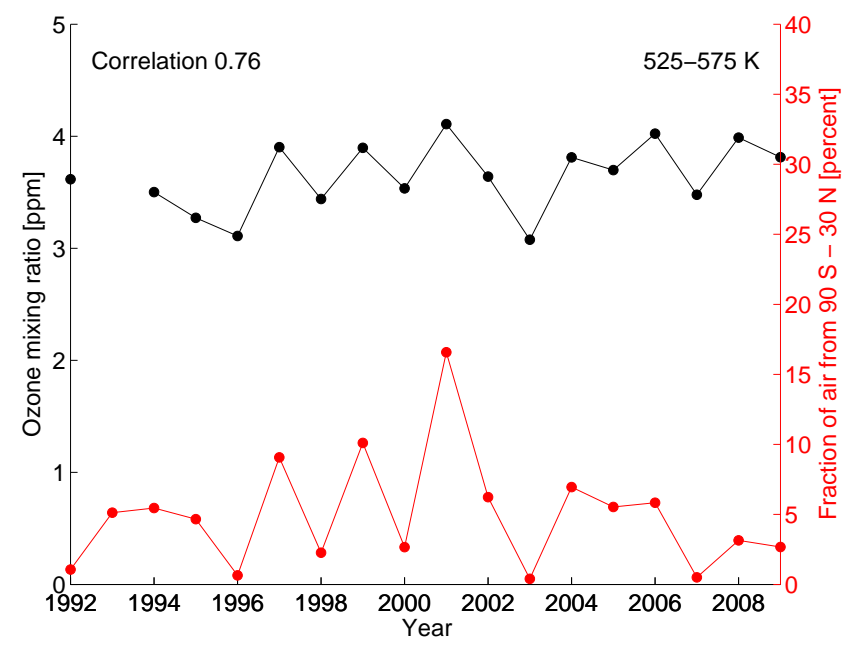

Fig. 6. Time series of vortex mean ozone mixing ratios at 525$575 \mathrm{~K}$ in early winter (30 December-8 January, 1992-2009, black), superimposed by a time series of the fraction of air in the polar vortex at $525-575 \mathrm{~K}$ which is originating south of $30^{\circ} \mathrm{N}$ equivalent latitude on 1 September (red).

in the vortex in early winter at the same potential temperature level $525-575 \mathrm{~K}$ originating from equivalent latitudes south of $30^{\circ} \mathrm{N}$ on 1 September (regardless of potential temperature on 1 September, red). This corresponds to the first column of tracers in Fig. 4. It can be seen that a high fraction of low latitude air masses is related to high ozone mixing ratios. Note that both time series show no significant trend and that the correlation is due to interannual variability. In particular, there is no significant trend in ozone caused by the trend in ozone-depleting substances in the considered time period. The correlation coefficient of the detrended time series is 0.76 . Correspondingly, high ozone mixing ratios are related to a low fraction of air from high latitudes. Figure 7 shows the same ozone time series as before, but now the fraction of air originating from equivalent latitudes between 70 $75^{\circ} \mathrm{N}$. The correlation coefficient of the detrended time series is -0.78 .

Figure 8 generalizes Figs. 6 and 7. The figure shows the correlation coefficients of the time series of vortex mean ozone mixing ratios in early winter at $525-575 \mathrm{~K}$ with several time series of origin tracers as a function of equivalent latitude. The time series of the origin tracers are the fraction of air in the vortex in early winter at $525-575 \mathrm{~K}$ originating from the equivalent latitude interval given at the horizontal axis on 1 September. Correlations significant at the $95 \%$ level are shown in blue. The time series are detrended in this figure and all following figures.

Figure 9 takes the generalization one step further. Each colored box shows the correlation coefficient of a time series of vortex mean ozone mixing ratios in early winter and a time series of an origin tracer in early winter. The ozone time series is averaged over the potential temperature layers

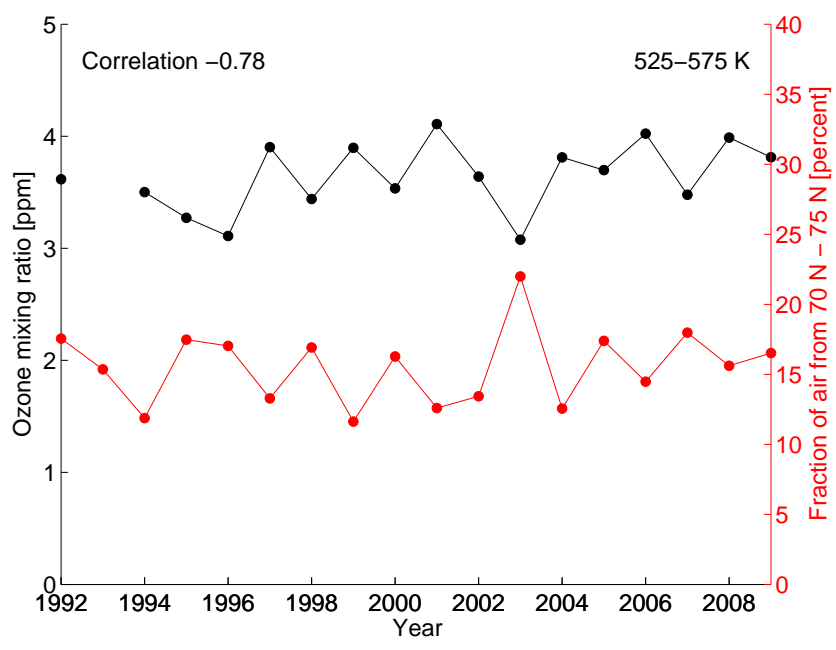

Fig. 7. Time series of vortex mean ozone mixing ratios at 525$575 \mathrm{~K}$ in early winter (30 December-8 January, 1992-2009, black), superimposed by a time series of the fraction of air in the polar vortex at $525-575 \mathrm{~K}$ which is originating from $70-75^{\circ} \mathrm{N}$ equivalent latitude on 1 September (red).

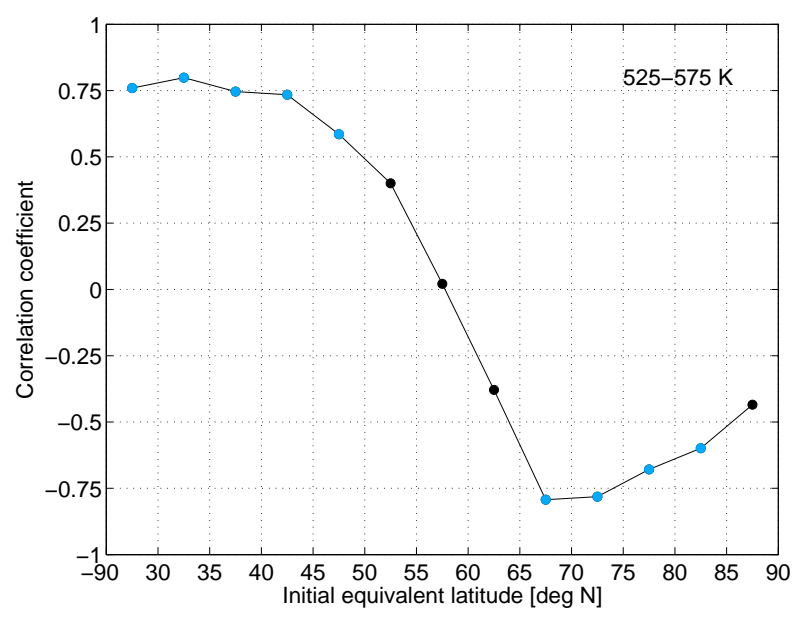

Fig. 8. Correlation of the origin of air inside the polar vortex and vortex mean ozone mixing ratios at $525-575 \mathrm{~K}$. Correlation of a time series (1992-2009) of vortex mean ozone mixing ratios in early winter at $525-575 \mathrm{~K}$ and a time series of the fraction of air in the vortex in early winter at $525-575 \mathrm{~K}$ originating from the equivalent latitude intervals given at the horizontal axis on 1 September. Correlation coefficients significant at the $95 \%$ level are shown in blue. Time series are detrended.

indicated at the vertical axis. The labels of the axis give the endpoints of the $50 \mathrm{~K}$ intervals. The time series of the origin tracer is the fraction of vortex air in early winter originating from the equivalent latitude intervals given at the horizontal axis on 1 September and averaged over the potential temperature intervals given at the vertical axis. E.g. the correlation coefficient of the two time series from Fig. 6 can be found in the first column and at the row between the labels $525 \mathrm{~K}$ 


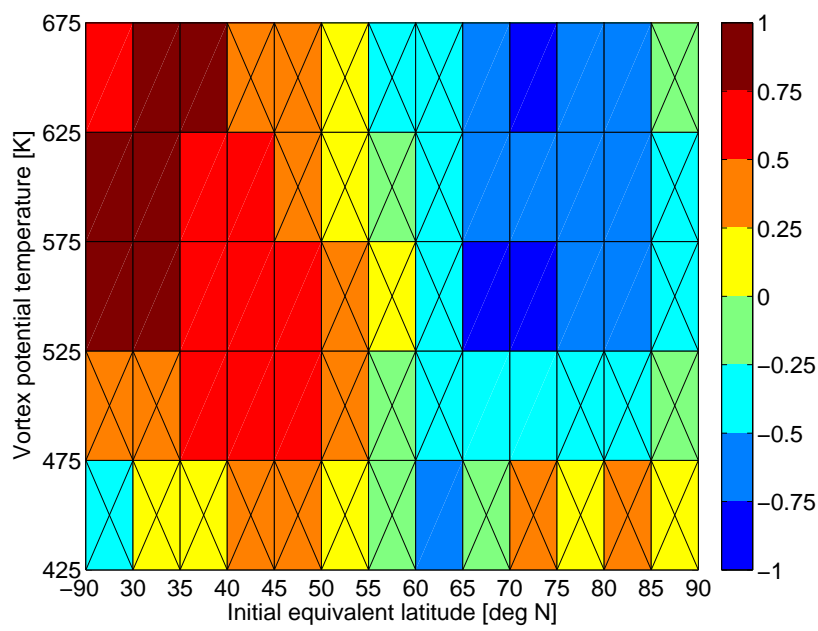

Fig. 9. Correlation of the origin of air inside the polar vortex and vortex mean ozone mixing ratios. Each colored box shows the correlation coefficient of a time series of vortex mean ozone mixing ratios in early winter and a time series of an origin tracer in early winter (1992-2009). The ozone time series is averaged over the potential temperature layers indicated at the vertical axis. The labels of the axis give the endpoints of the $50 \mathrm{~K}$ intervals. The time series of the origin tracer is the fraction of vortex air in early winter originating from the equivalent latitude intervals given at the horizontal axis on 1 September and averaged over the potential temperature intervals given at the vertical axis. Correlation coefficients not significant at the $95 \%$ level are crossed out. Time series are detrended.

and $575 \mathrm{~K}$. Correlation coefficients not significant at the $95 \%$ level are crossed out.

The figure shows that high positive correlation coefficients occur at low equivalent latitudes at most potential temperature levels, which means that a high abundance of air from lower latitudes corresponds to high ozone mixing ratios inside the polar vortex in all altitudes. Accordingly, a high amount of air masses from high latitudes corresponds to low ozone mixing ratios at most potential temperature levels.

Figure 10 shows the same data as Fig. 9, but now the origin tracer is the fraction of vortex air in early winter originating from a certain initial potential temperature interval on 1 September.

Note that we will use the term "net Lagrangian subsidence" in the following in the sense of the Lagrangian subsidence along the transport path of an air parcel between 1 September and early winter. This is different from the usual definition in the Transformed Eulerian Mean (TEM) sense at a fixed location in latitude and pressure (Andrews et al., 1987), which does not refer to the same air mass as time proceeds. These two definitions can lead to very different results.

The black line in Fig. 10 is the line of zero Lagrangian subsidence. The positive correlation coefficients near the line of zero Lagrangian subsidence (for vortex potential temperature levels near the initial potential temperature levels) indicate that higher vortex mean ozone mixing ratios in early winter

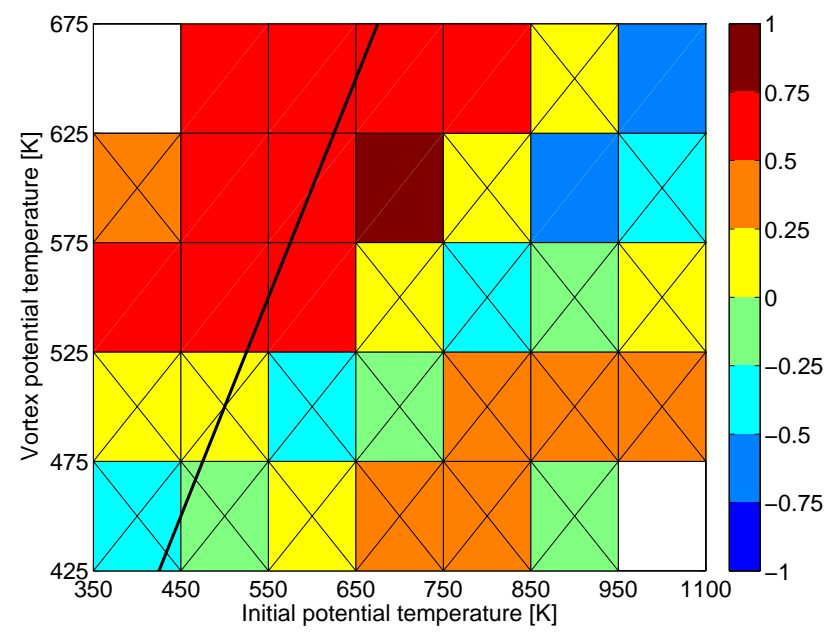

Fig. 10. Same as Fig. 9, but now the origin tracer is the fraction of vortex air in early winter originating from the potential temperature interval given at the horizontal axis on 1 September. Correlation coefficients not significant at the $95 \%$ level are crossed out. The black line is the line of zero Lagrangian subsidence. Time series are detrended.

are typically correlated with a higher abundance of air from lower initial potential temperature levels on 1 September (respectively with less net Lagrangian subsidence). At first, that seems to be in contradiction to the typical increase of ozone mixing ratios with potential temperature.

However, an origin from a certain potential temperature level is also correlated with a preferred latitudinal origin, which is shown in Fig. 11. The figure shows a scatter plot of the vortex mean of two origin tracers in early winter at 525$575 \mathrm{~K}$. Each marker gives the values of the two tracers in the particular year shown inside the marker. The tracer on the horizontal axis is the fraction of air originating from equivalent latitudes south of $30^{\circ} \mathrm{N}$ on 1 September. The tracer on the vertical axis is the fraction of air originating from the initial potential temperature interval $550-650 \mathrm{~K}$ on 1 September (i.e. with a maximum of $125 \mathrm{~K}$ Lagrangian subsidence).

Figure 11 indicates that an origin in southern or tropical latitudes is typically correlated with less net Lagrangian subsidence (lower initial potential temperatures) than an origin in higher latitudes. This is consistent with ascent (in the TEM sense) in the tropics and subsidence (in the TEM sense) in polar regions, as expected from the Brewer-Dobson circulation: on average, air will spent more time in low latitudes if it originates in low latitudes, and hence more time in regions with upwelling or weak downwelling. Since ozone mixing ratios are higher at the same potential temperature level in the tropics than in the polar regions in the considered altitude range, less Lagrangian subsidence is correlated with higher ozone mixing ratios.

This is schematically illustrated in Fig. 12. Figure 12 shows the mean ozone distribution in September as 


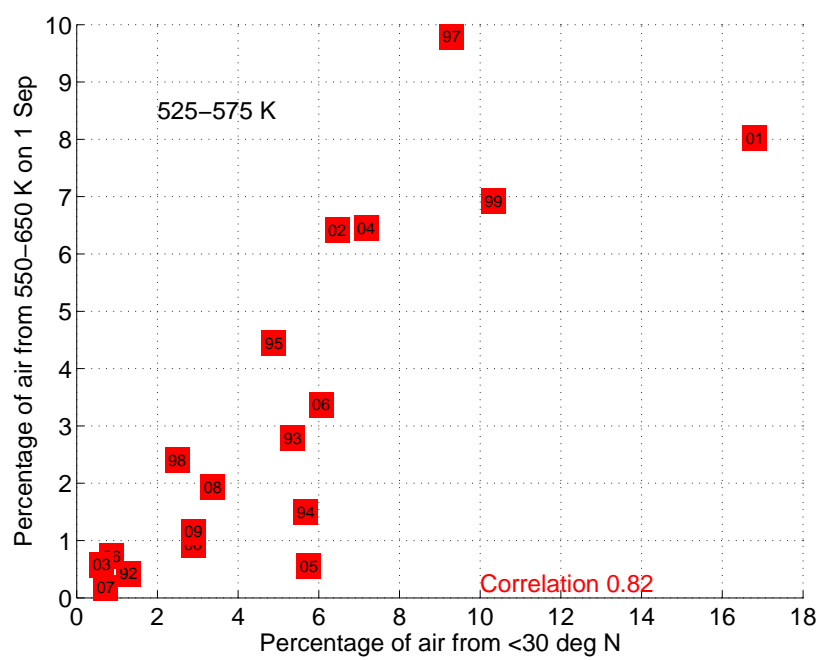

Fig. 11. Scatter plot of the vortex mean of two origin tracers in early winter at $525-575 \mathrm{~K}$. Each marker gives the values of the two tracers in the particular year shown inside the marker. The tracer on the horizontal axis is the fraction of air originating from equivalent latitudes south of $30^{\circ} \mathrm{N}$ on 1 September. The tracer on the vertical axis is the fraction of air originating from the initial potential temperature interval $550-650 \mathrm{~K}$ on 1 September (i.e. with a maximum of $125 \mathrm{~K}$ Lagrangian subsidence).

a function of potential temperature and equivalent latitude. Pathway 1 shows the situation in years with a high fraction of air from low latitudes enclosed in the vortex, which is typically also connected with low net Lagrangian subsidence. Due to the mean ozone distribution, this leads to relatively high ozone values in the vortex. This situation should also typically be connected to a strong Brewer-Dobson circulation, enhanced meridional mixing and a high EP flux through the tropopause (Andrews et al., 1987). We will show the relationship between EP flux and origin of air (respectively ozone) in more detail in the next sections. The correlation between EP flux and ozone (but not origin of air) has already been the subject of many studies (e.g. Fusco and Salby, 1999; Weber et al., 2003). Note that low net Lagrangian subsidence is connected here to a strong Brewer-Dobson circulation, and hence, a high subsidence in the TEM sense in high latitudes. This is no contradiction as long as the air spends not too much time in the region of high subsidence.

Pathway 2 shows the situation in years with a low fraction of air from low latitudes enclosed in the vortex, which is typically connected with high Lagrangian subsidence, low ozone and a weak Brewer-Dobson circulation.

\section{EP flux and origin of air}

The divergence of the EP flux is a measure for the momentum deposited in the middle atmosphere by breaking waves that are propagating from the troposphere to the stratosphere

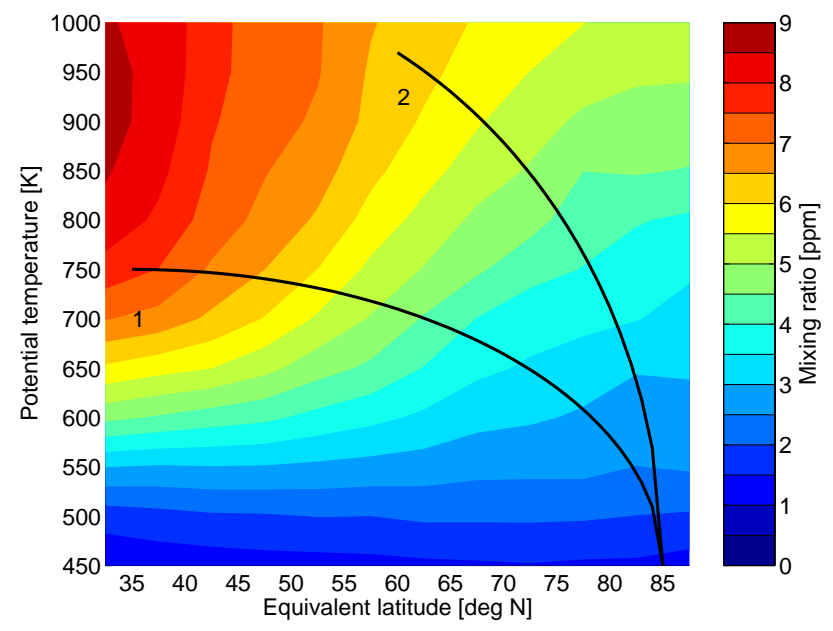

Fig. 12. Schematical illustration of the pathway of air in two years with extreme conditions. Colors show the mean ozone distribution in September. Pathway 1 shows the situation in years with a high fraction of air from low latitudes enclosed in the vortex, which is typically also connected with low net Lagrangian subsidence. Due to the mean ozone distribution, this leads to relatively high ozone values in the vortex. This situation is also typically connected with a strong Brewer-Dobson circulation and a high EP flux through the tropopause. Pathway 2 shows the situation in years with a low fraction of air from low latitudes enclosed in the vortex, which is typically connected with high net Lagrangian subsidence, low ozone and a weak Brewer-Dobson circulation.

(e.g. Andrews et al., 1987). Both the strength of the zonal mean residual circulation and of meridional mixing are related to the amount of momentum deposited in the stratosphere (Andrews et al., 1987). The residual circulation below a given pressure level can only be influenced by waves breaking above this level (downward control principle, see Haynes et al., 1991). EP flux enters the stratosphere mainly through the mid-latitude tropopause. The EP flux in autumn for a given pressure level is given here as the vertical component of the flux through this level averaged over $45-75^{\circ} \mathrm{N}$ and from September to November. This equals in good approximation the overall divergence above this level in autumn. Each potential temperature layer in our analysis is assigned a pressure level by averaging over the pressure in the layer. EP flux is used intentionally here as a single-valued proxy for complicated dynamical processes and to show up the basic relationships.

Figure 13 shows the correlation between several time series of origin tracers at $525-575 \mathrm{~K}$ and the EP flux through this layer in autumn (to consider the downward control principle) as a function of equivalent latitude, in the same manner as in Fig. 8. I.e. the time series of the origin tracers are the fraction of air in the vortex in early winter at $525-575 \mathrm{~K}$ originating from the equivalent latitude interval given at the horizontal axis on 1 September. High amounts of air masses from lower latitudes are correlated with enhanced EP flux, as 


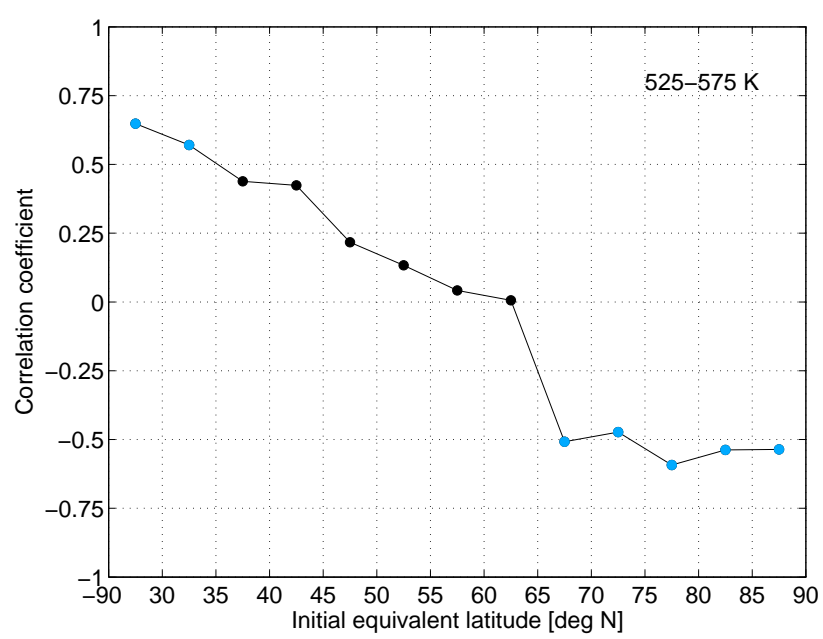

Fig. 13. Correlation of the origin of air inside the polar vortex and EP flux through mid latitudes in autumn. Correlation of a time series (1992-2009) of the vertical component of the EP flux through a pressure level equivalent to $525-575 \mathrm{~K}$ averaged over $45-75^{\circ} \mathrm{N}$ and from September to November and a time series of the fraction of air in the vortex in early winter at $525-575 \mathrm{~K}$ originating from the equivalent latitude intervals given at the horizontal axis on 1 September. Correlation coefficients significant at the $95 \%$ level are shown in blue. Time series are detrended.

expected by the mechanisms of the Brewer-Dobson circulation.

Figure 14 again generalizes Fig. 13. Now, each colored box shows the correlation coefficient of a time series of EP flux through a layer in autumn and a time series of an origin tracer at this layer in early winter. The time series of the origin tracer is the fraction of vortex air in early winter originating from the equivalent latitude intervals given at the horizontal axis on 1 September and averaged over the potential temperature intervals given at the vertical axis, in the same manner as in Fig. 9. The EP flux is calculated for the potential temperature layers at the vertical axis, but is no function of the horizontal axis.

The figure shows that high amounts of air masses from lower latitudes are correlated with enhanced EP flux at all altitude levels and that high amounts of air masses from high latitudes are anti-correlated with the EP flux.

There is some sensitivity with respect to the averaging period of the EP flux in the correlations. Correlations are best for September to November, which most closely matches the period with enhanced meridional mixing. Both the periods September to October and September to December show lower correlations.

\section{EP flux and ozone}

If both vortex mean ozone in early winter and EP flux in autumn correlate with the origin of air, it is to be expected

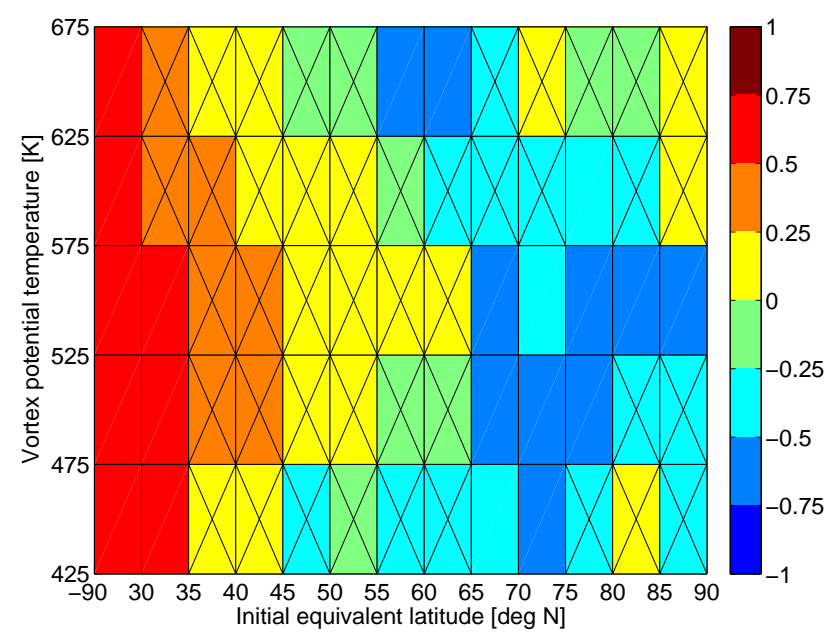

Fig. 14. Correlation of the origin of air inside the polar vortex and EP flux through mid latitudes in autumn. Each colored box shows the correlation coefficient of a time series of EP flux through a layer in autumn and a time series of an origin tracer in early winter at the same layer (1992-2009). The EP flux time series is the vertical component of the flux through the layer given at the vertical axis averaged over $45-75^{\circ} \mathrm{N}$ and from September to November. The origin tracer is the fraction of vortex air in early winter originating from the equivalent latitude intervals given at the horizontal axis on 1 September and averaged over the potential temperature intervals given at the vertical axis. Correlation coefficients not significant at the $95 \%$ level are crossed out. Time series are detrended.

that also ozone and EP flux correlate with each other, as already shown for other cases by several studies (e.g. Fusco and Salby, 1999; Weber et al., 2003). Figure 15 shows the correlation between vortex mean ozone mixing ratios in early winter at a particular level and the EP flux in autumn through this level (all quantities are defined as in the last sections). While the correlations are not as high as in the other plots, there is a positive correlation between EP flux and ozone mixing ratio at the layers $525-575 \mathrm{~K}$ and $575-625 \mathrm{~K}$ (with a significance of $97 \%$ and $86 \%$, respectively).

Note that the correlations in the last two sections explain significantly less than $50 \%$ of the variance of the equivalent latitude tracer time series or ozone time series, which is not too surprising. While the EP flux through a level is directly associated with the residual circulation at this level (i.e. the subsidence in the TEM sense), meridional mixing is associated with the wave breaking (i.e. the EP flux divergence) at a particular level. Since the EP flux divergence is more prone to noise in the data than the EP flux and is notoriously difficult to calculate, and since both subsidence and meridional mixing play a role, we use EP flux as a compromise here. In addition, it is certainly important for the exact transport and mixing pathways at which latitudes and altitudes the waves break or what the wave numbers are. This is not resolved by using EP flux as a proxy. 


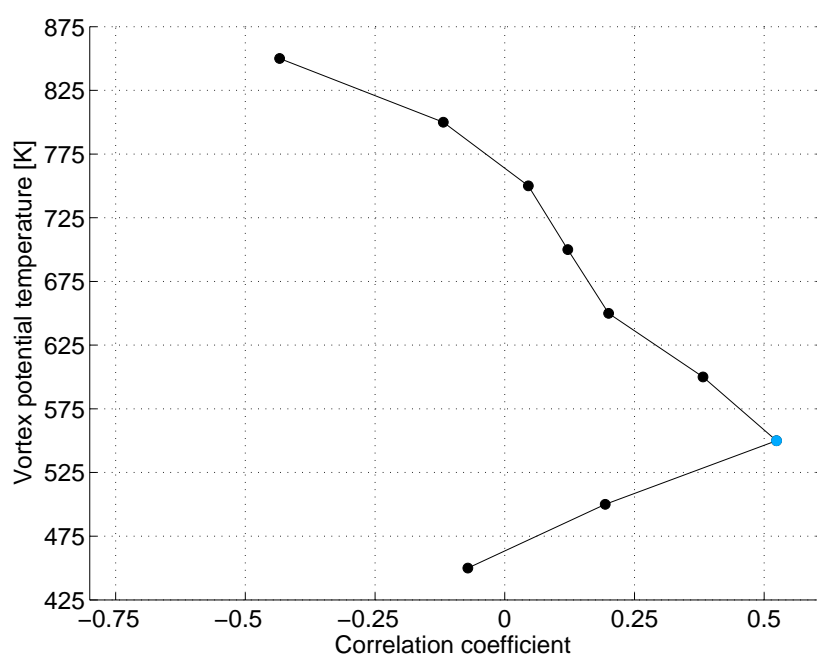

Fig. 15. Correlation of EP flux through mid latitudes in autumn and vortex mean ozone mixing ratios in early winter. The EP flux time series is the vertical component of the flux through the layer given at the vertical axis averaged over $45-75^{\circ} \mathrm{N}$ and from September to November. The ozone time series is the vortex mean ozone mixing ratio in early winter at the given layer. Correlation coefficients significant at the $95 \%$ level are shown in blue. Time series are detrended.

\section{Conclusions}

We have used model runs of the ATLAS CTM in conjunction with a comprehensive ozone dataset based on sondes and satellites to deduce statistical relationships between the ozone amount in the polar vortex in early winter and the latitudinal and vertical origin of air in September. For this, we used a set of artificial model tracers of air mass origin initialized in September and transported with the model until early January, when the distributions of the tracers were correlated with the ozone amount in the vortex. In addition, we examined the relationship between the wave activity in autumn (represented by the EP flux through the mid-latitude tropopause from September to November) and both the origin of air and the ozone amount in the early winter polar vortex. Our main findings are:

- Both high wave activity and high ozone are connected to a large fraction of vortex air originating from low latitudes at the beginning of autumn. This air has typically experienced relatively small net subsidence (in a Lagrangian sense) in autumn.

- High wave activity during polar vortex formation in autumn leads to high mixing ratios of ozone enclosed into the vortex at the beginning of winter (and vice versa).

This is in line with earlier results for other seasons (e.g. Fusco and Salby, 1999) and with expectations from basic mechanisms of the Brewer-Dobson circulation (e.g. Andrews et al., 1987). The relationships between air mass origin and EP flux or ozone have not been examined in detail so far for the autumn season to our knowledge. The use of the artificial origin tracers (e.g. Günther et al., 2008) enables a direct and intuitive study of the origin of air masses, which is not possible with indirect methods like the measurement of chemically conserved species.

Our study qualitatively confirms the results of Rosenfield and Schoeberl (2001). Rosenfield and Schoeberl (2001) show that in each year, there are two populations of air parcels ending up in the vortex: air parcels that experience high subsidence and often originate from the upper stratosphere and mesosphere, and air parcels that experience low subsidence and typically originate from more southern latitudes. These populations contribute different fractions of the air parcels in the vortex in different years, which causes interannual variability in conserved tracers. There are also indications in this study that dynamically more active years have a greater contribution from the population with low descent rates.

In a companion paper, we show that below a critical altitude (about $750 \mathrm{~K}$ ), the chemical lifetime of ozone is long enough to let transport dominate over chemistry (Blessmann et al., 2012).

Acknowledgements. We thank ECMWF for providing reanalysis data and all PIs for providing ozone sonde data. Work at AWI was partially supported by the EC project RECONCILE, Grant Agreement No. 236365.

Edited by: M. Dameris

\section{References}

Andrews, D. G., Holton, J. R., and Leovy, C. B.: Middle Atmosphere Dynamics, Academic Press, 1987.

Blessmann, D., Wohltmann, I., Lehmann, R., and Rex, M.: Persistence of ozone anomalies in the Arctic stratospheric vortex in autumn, Atmos. Chem. Phys., 12, 4817-4823, doi:10.5194/acp12-4817-2012, 2012.

Butchart, N. and Remsberg, E. E.: The area of the stratospheric polar vortex as a diagnostic for tracer transport on an isentropic surface, J. Atmos. Sci., 43, 1319-1339, 1986.

Charney, J. G. and Drazin, P. G.: Propagation of planetary-scale disturbances from the lower into the upper atmosphere, J. Geophys. Res., 66, 83-109, 1961.

Dee, D. P., Uppala, S. M., Simmons, A. J., Berrisford, P., Poli, P., Kobayashi, S., Andrae, U., Balmaseda, M. A., Balsamo, G., Bauer, P., Bechtold, P., Beljaars, A. C. M., van de Berg, L., Bidlot, J., Bormann, N., Delsol, C., Dragani, R., Fuentes, M., Geer, A. J., Haimberger, L., Healy, S. B., Hersbach, H., Hólm, E. V., Isaksen, L., Kållberg, P., Köhler, M., Matricardi, M., McNally, A. P., Monge-Sanz, B. M., Morcrette, J.-J., Park, B.-K., Peubey, C., de Rosnay, P., Tavolato, C., Thépaut, J.-N., and Vitart, F.: The ERA-Interim reanalysis: configuration and performance of the data assimilation system, Q. J. Roy. Meteorol. Soc., 137, 553597, 2011. 
Fahey, D. W. and Ravishankara, A. R.: Summer in the stratosphere, Science, 285, 208-210, 1999.

Fioletov, V. E. and Shepherd, T. G.: Seasonal persistence of midlatitude total ozone anomalies, Geophys. Res. Lett., 30, 1417, doi:10.1029/2002GL016739, 2003.

Frieler, K., Rex, M., Salawitch, R. J., Canty, T., Streibel, M., Stimpfle, R. M., Pfeilsticker, K., Dorf, M., Weisenstein, D. K., and Godin-Beekmann, S.: Toward a better quantitative understanding of polar stratospheric ozone loss, Geophys. Res. Lett., 33, L10812, doi:10.1029/2005GL025466, 2006.

Fusco, A. C. and Salby, M. L.: Interannual variations of total ozone and their relationship to variations of planetary wave activity, J. Climate, 12, 1619-1629, 1999.

Günther, G., Müller, R., von Hobe, M., Stroh, F., Konopka, P., and Volk, C. M.: Quantification of transport across the boundary of the lower stratospheric vortex during Arctic winter 2002/2003, Atmos. Chem. Phys., 8, 3655-3670, doi:10.5194/acp-8-36552008, 2008.

Haynes, P. H., Marks, C. J., McIntyre, M. E., Shepherd, T. G., and Shine, K. P.: On the "downward control" of extratropical diabatic circulations by eddy-induced mean zonal forces, J. Atmos. Sci., 48, 651-678, 1991.

Kawa, S. R., Bevilacqua, R. M., Margitan, J. J., Douglass, A. R., Schoeberl, M. R., Hoppel, K. W., and Sen, B.: Interaction between dynamics and chemistry of ozone in the setup phase of the Northern Hemisphere polar vortex, J. Geophys. Res., 108, 8310, doi:10.1029/2001JD001527, 2003.

Kawa, S. R., Newman, P. A., Stolarski, R. S., and Bevilacqua, R. M.: Fall vortex ozone as a predictor of springtime total ozone at high northern latitudes, Atmos. Chem. Phys., 5, 1655-1663, doi:10.5194/acp-5-1655-2005, 2005.

Legras, B. and Fueglistaler, S.: Age of air and heating rates: comparison of ERA-40 with ERA-Interim, presentation at EGU General Assembly, Vienna, 2009.

Lumpe, J. D., Bevilacqua, R. M., Hoppel, K. W., Krigman, S. S., Kriebel, D. L., Debrestian, D. J., Randall, C. E., Rusch, D. W., Brogniez, C., Ramananahérisoa, R., Shettle, E. P., Olivero, J. J., Lenoble, J., and Pruvost, P.: POAM II retrieval algorithm and error analysis, J. Geophys. Res., 102, 23593-23614, 1997.

Lumpe, J. D., Bevilacqua, R. M., Hoppel, K. W., and Randall, C. E.: POAM III retrieval algorithm and error analysis, J. Geophys. Res., 107, 4575, doi:10.1029/2002JD002137, 2002.
McCormick, M. P., Zawodny, J. M., Veiga, R. E., Larsen, J. C., and Wang, P.: An overview of SAGE I and SAGE II ozone measurements, Planet. Space Sci., 37, 1567-1586, 1989.

Nakajima, H., Sugita, T., Yokota, T., and Sasano, Y.: Atmospheric environment monitoring by the ILAS-II onboard the ADEOS-II satellite, Proc. SPIE, 5571, 293-300, 2004.

Rosenfield, J. E. and Schoeberl, M. R.: On the origin of polar vortex air, J. Geophys. Res., 106, 33485-33497, 2001.

Russell III, J. M., Gordey, L. L., Park, J. H., Drayson, S. R., Hesketh, D. H., Cicerone, R. J., Tuck, A. F., Frederick, J. E., Harries, J. E., and Crutzen, P.: The Halogen Occultation Experiment, J. Geophys. Res., 98, 10777-10797, 1993.

Schoeberl, M. R. and Hartmann, D. L.: The dynamics of the stratospheric polar vortex and its relation to springtime ozone depletions, Science, 251, 46-52, 1991.

Sinnhuber, B.-M., von der Gathen, P., Sinnhuber, M., Rex, M., König-Langlo, G., and Oltmans, S. J.: Large decadal scale changes of polar ozone suggest solar influence, Atmos. Chem. Phys., 6, 1835-1841, doi:10.5194/acp-6-1835-2006, 2006.

Tilmes, S., Müller, R., Grooß, J.-U., Nakajima, H., and Sasano, Y.: Development of tracer relations and chemical ozone loss during the setup phase of the polar vortex, J. Geophys. Res., 111, D24S90, doi:10.1029/2005JD006726, 2006.

Weber, M., Dhomse, S., Wittrock, F., Richter, A., Sinnhuber, B.M., and Burrows, J. P.: Dynamical control of NH and SH winter/spring total ozone from GOME observations in 1995-2002, Geophys. Res. Lett., 30, 1583, doi:10.1029/2002GL016799, 2003.

WMO: World Meteorological Organization (WMO)/United Nations Environment Programme (UNEP), Scientific assessment of ozone depletion: 2010, Global Ozone Research and Monitoring Project - Report No. 52, 2011.

Wohltmann, I. and Rex, M.: The Lagrangian chemistry and transport model ATLAS: validation of advective transport and mixing, Geosci. Model Dev., 2, 153-173, doi:10.5194/gmd-2-153-2009, 2009.

Wohltmann, I., Lehmann, R., and Rex, M.: The Lagrangian chemistry and transport model ATLAS: simulation and validation of stratospheric chemistry and ozone loss in the winter 1999/2000, Geosci. Model Dev., 3, 585-601, doi:10.5194/gmd-3-585-2010, 2010. 